\title{
MOODLE QUESTIONNAIRES AS A SELF-ASSESSMENT TOOL FOR MEETING THE CHALLENGES OF DIVERSITY IN STUDENTS' BACKGROUND KNOWLEDGE
}

\author{
Ester Sales-Setién, Ignacio Peñarrocha-Alós \\ Universitat Jaume I de Castelló (SPAIN)
}

\begin{abstract}
Process Automation and Advanced Control is a subject of the master's degree in Industrial Engineering from the Universitat Jaume I de Castelló that seeks to develop the students' ability to design automated production systems and advanced process controllers. In order to properly acquire the specific competences of this master's degree subject, the students should master some basic concepts of control systems that are generally acquired at a bachelor's degree level. The teachers of the subject find that the background knowledge of the master students is diverse because the students have studied different bachelor's degrees at different European universities. The content of the subject being dense, the lecturers have little room for manoeuvre in order to review and reinforce this necessary prior knowledge during the lessons. In this work, we present a tool that allows the students to self-assess their prior knowledge. The tool has been implemented in Moodle and it consists of a variety of questionnaires with instantaneous feedback that guides each student on the learning materials that he should review in order to fill his gaps in background knowledge.
\end{abstract}

Keywords: background knowledge, self-assessment, Moodle, feedback.

\section{INTRODUCTION}

In order to study the subject Process Automation and Advanced Control, which is a compulsory subject of the master's degree in Industrial Engineering from the Universitat Jaume I, some background knowledge related to system modeling and process control is necessary. This prior knowledge is fundamental in order to properly acquire the general and specific competences assigned to the subject [1]. The contents related to this background knowledge are mainly studied at the subject Automatic Control Systems, which is a third-year subject of most of the degrees in engineering from the Universitat Jaume I. The master's degree in Industrial Engineering gathers students that we classify into two different groups: students who have completed the subject Automatic Control Systems at the Universitat Jaume I and students who have acquired the knowledge related to this subject at another European university. This last group of students is significant because some of the students of the bachelor's degrees in engineering from the Universitat Jaume I carry out a double diploma with the Institut National des Sciences Appliquées in France. These students take the third and fourth year undergraduate courses in France. Both groups of students need to reinforce their background knowledge of control systems. On the one hand, there is a time lag of two courses between the completion of the subject Automatic Control Systems and the beginning of the subject Process Automation and Advanced Control; thus, the students who have completed the subject Automatic Control Systems need to reinforce and practice the acquired competences. On the other hand, the students who have not taken this course at the Universitat Jaume I have not acquired this prior knowledge from the same perspective; hence, these students need a more in-depth study of some key agenda items.

The master's degree subject Process Automation and Advanced Control is dense in content and, therefore, the lecturers cannot devote too many teaching hours to review the previous notions which are necessary for the understanding of the new concepts introduced in the subject. In addition, the formative diversity of the students makes it difficult to perform this task in the classroom. Thus, automated self-assessment appears as a suitable solution to this problem. Specifically, test questionnaires have demonstrated their effectiveness as automated self-assessment systems $[2,3]$. The large number of possibilities offered by web learning platforms such as Moodle facilitates the implementation of this type of self-assessment tools [4]. These platforms have advantages such as personalized feedback adjusted to the personal level of knowledge proved in the performed tasks.

The educational control engineering community has been making great efforts to adapt and improve traditional teaching methods $[5,6]$. Motivated by all these reasons, in this paper we propose to develop 
a series of Moodle questionnaires that allow reinforcing the previous knowledge of the students of the subject Automation and Advanced Control according to their individual needs.

\section{OBJECTIVES}

The objectives of the project are the following:

- To attend the diversity in previous knowledge of the students of the subject Automation and advanced process control.

- To adapt the review process of previous knowledge to the individual needs of each student.

- To promote the use of Information and Communication Technologies (ICT).

- To promote autonomous learning

- To improve the motivation of students by attending to their difficulty of starting a subject that requires prior knowledge that has not been put into practice in the last two years.

To achieve these objectives, the designed self-assessment system must include the following tools:

- Questionnaires of different level for the self-assessment of all previous knowledge.

- Questionnaires of different level for the self-assessment of each of the different concepts.

- Automatic feedback that indicates to each student the material that he should revise in order to improve the results obtained in the questionnaires.

- Automatic feedback with indications of the questionnaires that the student must complete after reviewing the indicated material in order to self-assess his progress.

\section{MOODLE SELF-ASSESMENT TOOL}

The background knowledge that students must master so as to successfully achieve the objectives of the subject Automation and Advanced Control can be classified into two main groups:

- Theoretical and practical knowledge regarding the modeling and identification of industrial systems.

- Theoretical and practical knowledge of PID controller adjustment through experimental techniques and model-based techniques.

In the following we detail the way in which the questions of the self-assessment questionnaires have been implemented and organized and we show how these questionnaires with automated feedback have been designed.

\subsection{Questions}

Moodle platform allows organizing the questions into categories. Thus, the formulated questions have been classified into four main blocks: theoretical questions of systems, practical questions of systems, theoretical questions of controllers and practical questions of controllers (see Figure 1). Another block has also been included with automation questions (Grafcet questions). In general, the students have shown a higher and more uniform level of prior knowledge of automation. Thus, the questionnaires will include some questions related to these concepts, but they will not focus on them. Within each category, the questions have been coded as shown in Figure 2. The coding reflects both the relationship between the questions and the type of question. In this way, the elaboration of questionnaires based on these questions becomes a simpler and more systematic task. The classification also facilitates the future development of the tool since it makes more evident how to enrich the tool with new questions.

Four kinds of questions have been implemented: multiple choice questions, true or false questions, numeric questions and parametric questions. The theoretical questions have been formulated using one of the first two types of questions while the practical questions have been formulated using multiple choice, numeric and parametric questions. Figures 3 and 4 show two examples of multiple choice questions. The question in Figure 3 requires some calculations and, therefore, we consider it as a practical question. The question of Figure 4 is theoretical. Figure 5 includes a numeric question 
and, finally, Figure 6 includes some details of the elaboration of a parametric question, where the data involved in the problem are random and the answer is calculated in a parametric way.

\section{Categorías de pregunta para 'Curso: \\ - Cuestiones (0) \\ - Cuestiones teóricas de sistemas (15) 向 $\leftarrow \downarrow$ \\ - Cuestiones teóricas de controladores (15) \\ - Cuestiones Grafcet (4) \\ if $\leftarrow$ 十 $\rightarrow$ \\ - Cuestiones prácticas de controladores (35) 向 \\ - Cuestiones prácticas de sistemas (20)}

Figure 1. Blocks of questions.

\begin{tabular}{|c|c|c|}
\hline \multicolumn{3}{|c|}{ Banco de preguntas } \\
\hline \multicolumn{3}{|c|}{$\square$ Mostrar el enunciado de la pregunta en la lista de preguntas } \\
\hline \multicolumn{3}{|c|}{$\begin{array}{l}\text { Opciones de búsqueda } \\
\text { Mostrar también preguntas de las sub-categorías }\end{array}$} \\
\hline \multicolumn{3}{|c|}{ Mostrar también preguntas antiguas } \\
\hline \multicolumn{3}{|c|}{ Crear una nueva pregunta... } \\
\hline \multicolumn{3}{|l|}{$\square^{\top}$ _ Pregunta } \\
\hline$\square$ 回 CoN1 & & $\%$ 饮 \\
\hline$\square$ CON2 & & क \\
\hline$\square$ 回 CON3 & & क 吅 Q 由 \\
\hline$\square$ CON4 & & 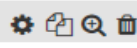 \\
\hline$\square$ CON5 & & 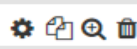 \\
\hline$\square:=$ CON1-1 & & क 死 Q 而 \\
\hline$\square: \equiv \operatorname{CON} 1-2$ & & क 吅 Q \\
\hline$\square: \equiv$ CON1-3 & & क 死 Q 由 \\
\hline$\square:=\operatorname{coN} 1-4$ & & क吅 Q 由 \\
\hline
\end{tabular}

Figure 2. Codification of the questions within a category.

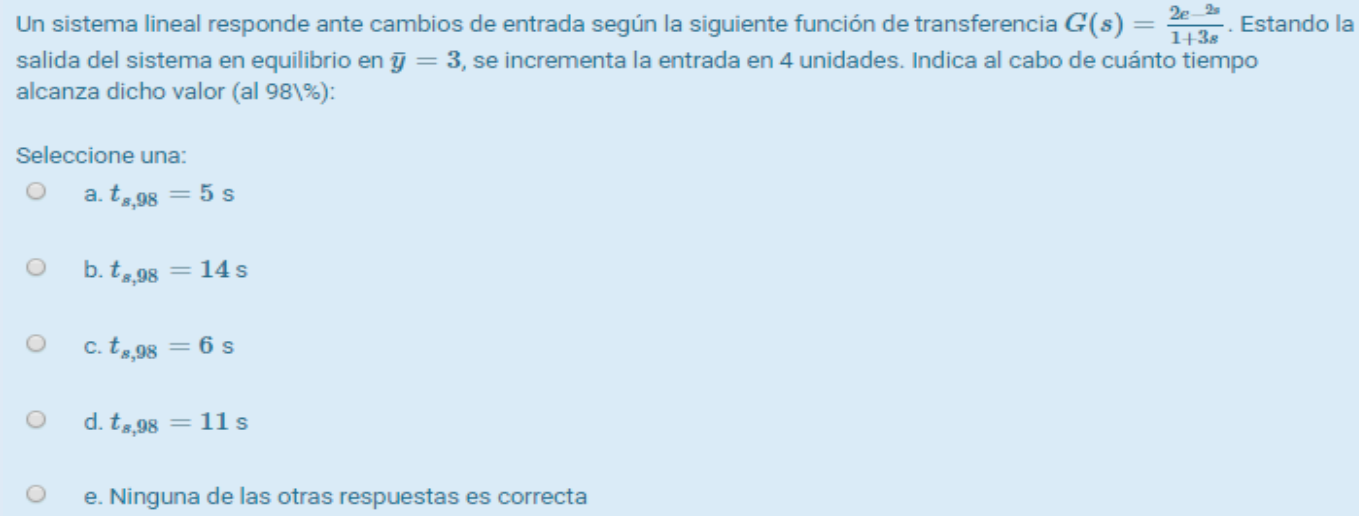

Figure 3. Example of practical multiple choice question. 
Un proceso cuyo modelo tiene integrador, controlado con un controlador PD:

Seleccione una:

a. Tiene error de posición nulo y error nulo ante perturbación escalón

b. Tiene error de posición finito y error finito ante perturbación escalón

c. Tiene error de posición nulo y error finito ante perturbación escalón

d. Ninguna de las otras respuestas es correcta

e. Tiene error de posición finito y error nulo ante perturbación escalón

Figure 4. Example of theoretical multiple choice question.

Indica el error en régimen permanente frente a perturbación rampa con C8

Respuesta:

Figure 5. Example of numeric question.

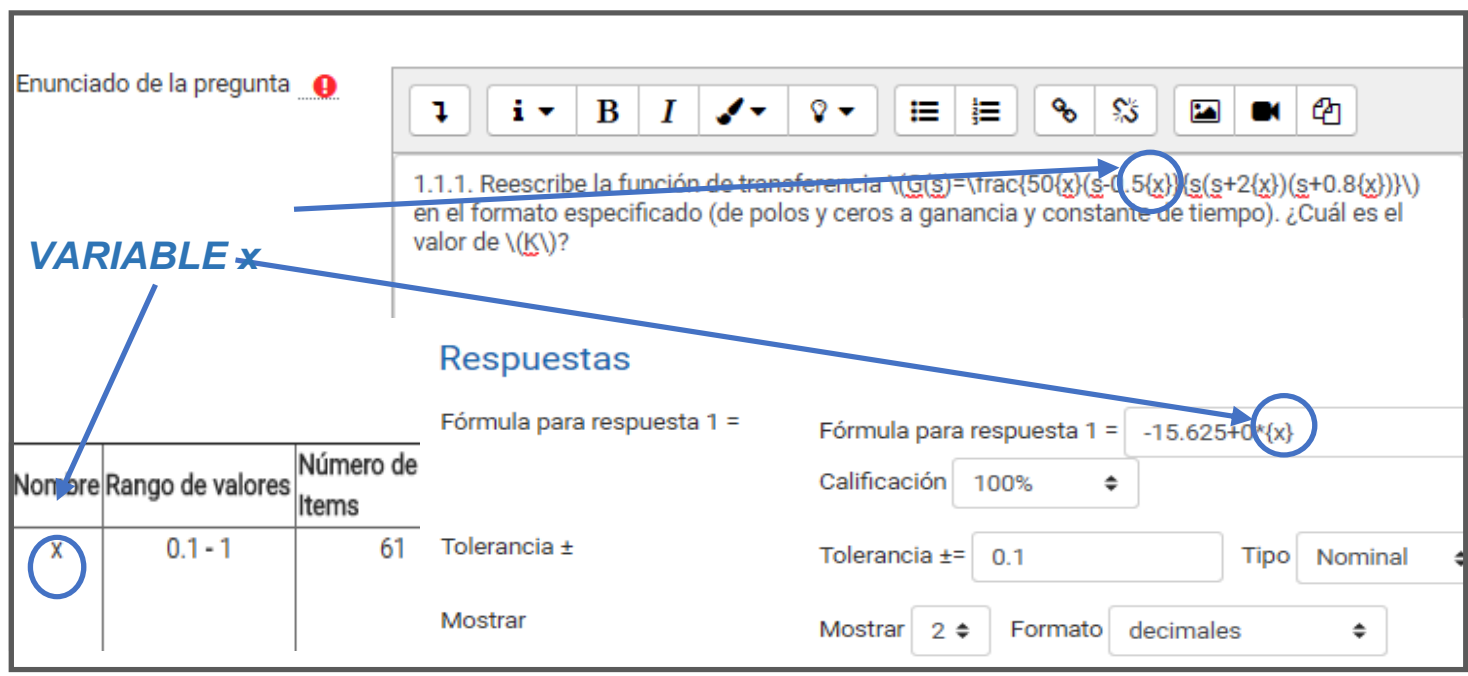

Figure 6. Example of parametric question. 


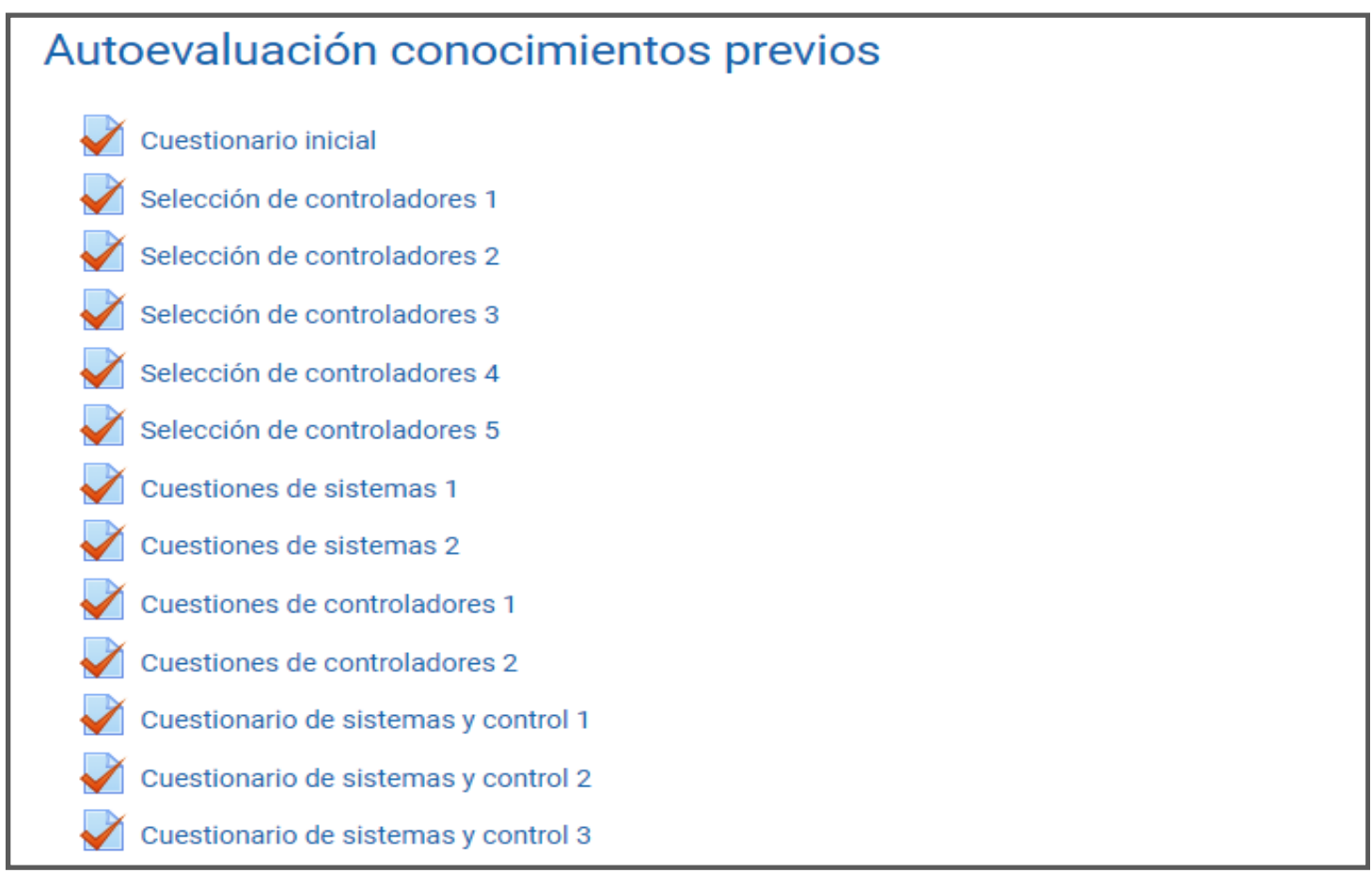

Figure 7. Organization of the questionnaires.

\subsection{Questionnaires}

The questionnaires have been included in a new section of the Moodle course of the master's subject Automation and Advanced Control. This new section is named as "Self-assessment of previous knowledge" (Figure 7). The questionnaires have also been included in the Moodle course of the bachelor's subject Automatic Control Systems in a new section called "Support material to prepare the exam".

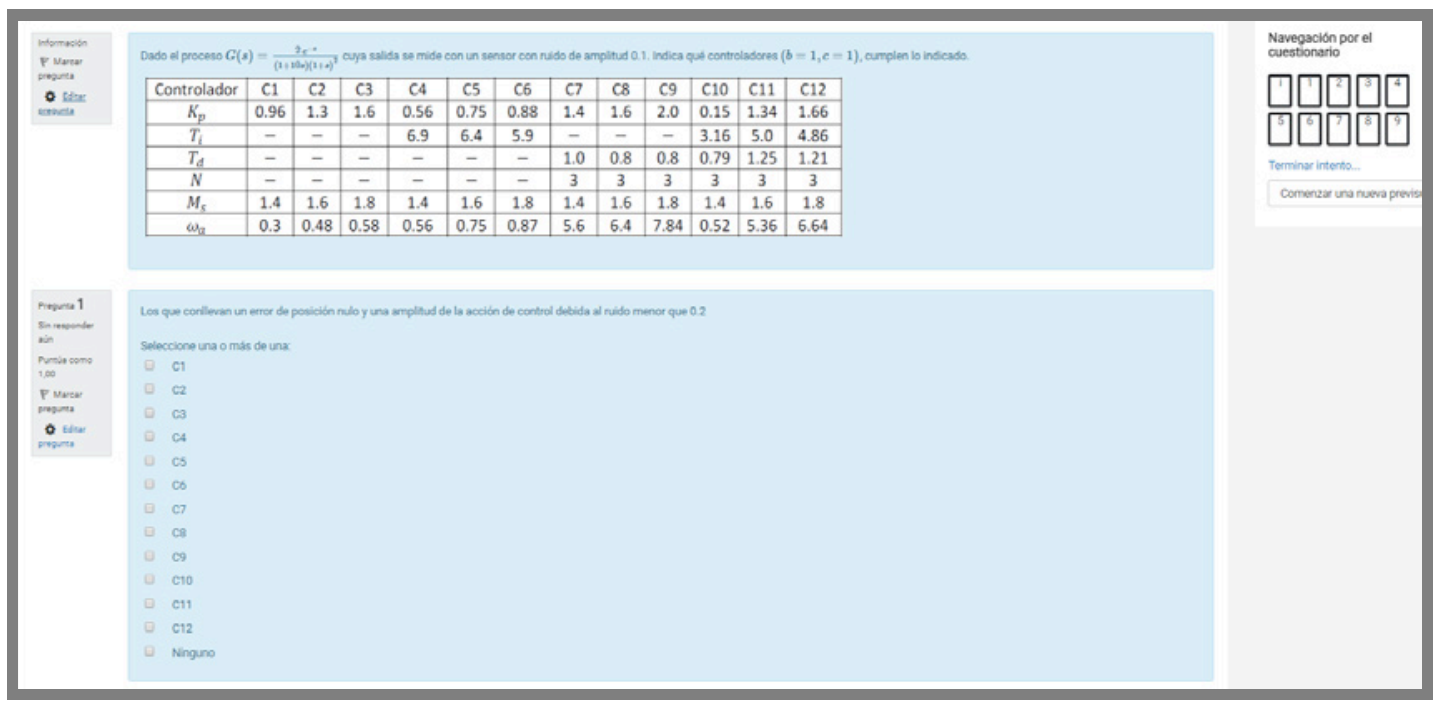

Figure 8. Cut-out of an implemented questionnaire with practical questions of controller.

We have developed four types of questionnaires: one for each of the four categories of questions detailed in Section 3.1. See Figure 8 for a cut-out of an implemented questionnaire. In addition, we have also created general questionnaires mixing questions from the four categories. These general questionnaires serve to carry out an initial self-assessment and one or several final self-assessments. Thus, the student should start with the initial self-assessment questionnaire. Depending on the obtained results, the materials to be reviewed and the following questionnaires to be completed will be indicated. If the results obtained are good, the student will directly prove his level of previous 
knowledge in the final questionnaires. If, on the other hand, the results obtained are not good in any of the four categories, the student must review the indicated material and move on to the questionnaires of that category . Once the results in all the categories are favorable, the student will complete the final questionnaire. The details of the provided feedback are explained below.

\subsection{Feedback}

In the general questionnaires, feedback will be provided in each of the questions answered erroneously. In the feedback of each question, the materials to consult will be indicated to the student. Moreover, the feedback includes information about the specific questionnaires that must be completed to work on the concepts related to that question. If the grade in the general questionnaire is higher than $75 \%$, a questionnaire feedback will indicate the student that he is prepared to continue with the following general questionnaire. The details of this feedback system are shown in Figure 9.

In the specific questionnaires only a final feedback of the whole questionnaire will be included. It will indicate to the student the steps to follow based on the grade obtained in the questionnaire. If the qualification is higher than $75 \%$, the student is already prepared to self-assess the specific concepts related to this questionnaire in a general questionnaire of final self-assessment. Thus, the student will be able to carry out this final self-assessment once positive feedbacks have been obtained in all the specific questionnaires that, according to the initial self-assessment questionnaire, he should complete. If, on the other hand, a student obtains a grade lower than $75 \%$ in a specific questionnaire, the student must continue working on the concepts related to this questionnaire and complete another specific questionnaire of the same type.

\section{CONCLUSIONS}

In this paper we have explained the implementation of a self-assessment tool in Moodle that addresses the diversity in previous knowledge of the students of the subject Process Automation and Advanced Control of the master's degree in Industrial Engineering from the Universitat Jaume I de Castelló. The tool has been programmed in Moodle and it consists of a series of questionnaires that deal with the background knowledge at different levels. The feedback of the questionnaires indicates the material that the student should review according to his results and it suggests the questionnaires to complete after reviewing the indicated contents. As future work, the tool presented in this paper will grow over the next academic years and it will serve as the skeleton of a more powerful tool that would contain a greater number of more complex and varied questions.

\section{GENERAL QUESTIONNAIRE}

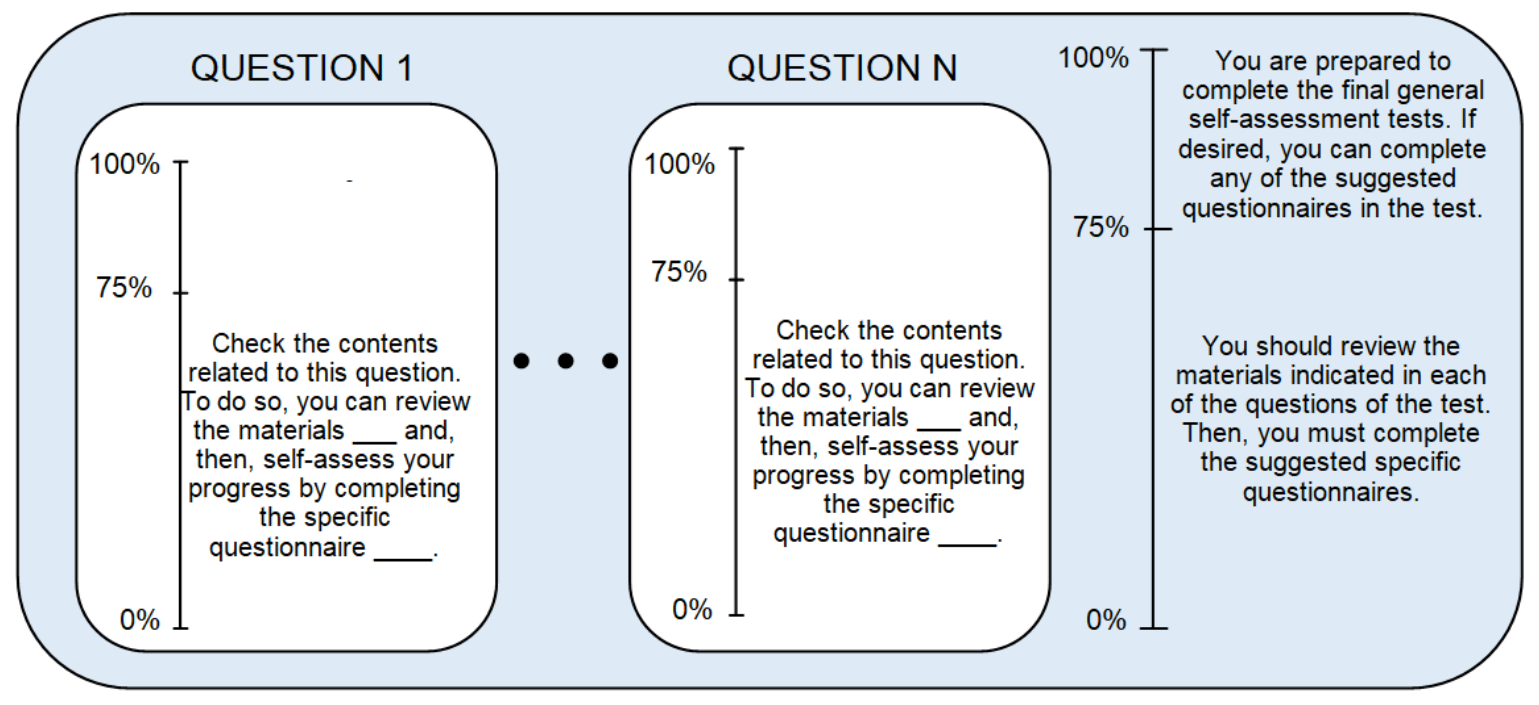

Figure 9. Scheme of the feedback in a general questionnaire. 


\section{SPECIFIC QUESTIONNAIRE}

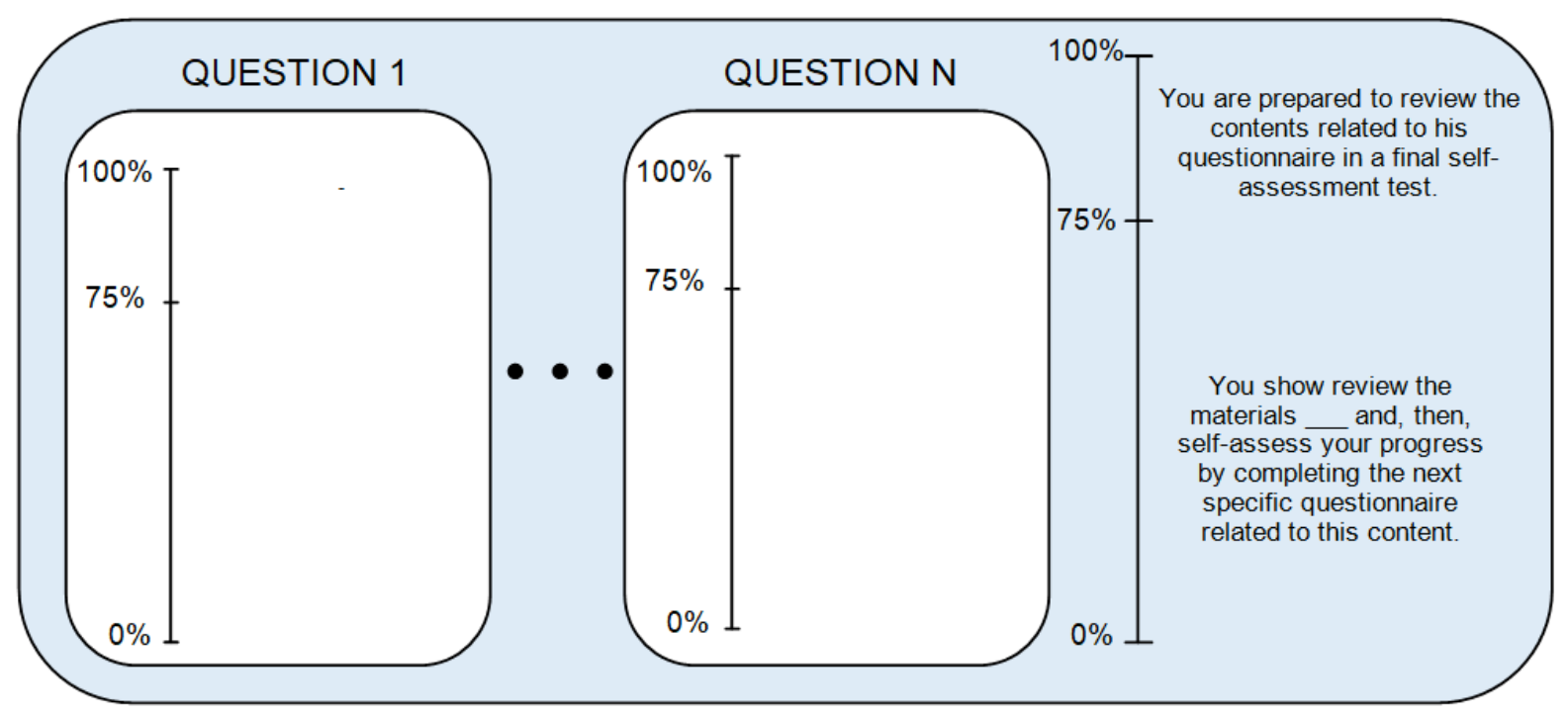

Figure 10. Scheme of the feedback in a specific questionnaire.

\section{ACKNOWLEDGEMENTS}

This work has been supported by the Spanish Ministry of Education, Culture and Sports (Grant no. FPU14/01592) and by the Universitat Jaume I through a grant received within the Novice teacher training program.

\section{REFERENCES}

[1] M. Miras, "Un punto de partida para el aprendizaje de nuevos contenidos: Ios conocimientos previos" in El constructivismo en el aula, 47-63, Barcelona, Graó, 1993.

[2] C. Maté, "Sistema automatizado de autoevaluación del aprendizaje basado en pruebas tipo test", III Jornades de Xarxes d'Investigació en Docència Universitària: la configuració de l'Espai Europeu d'Educació Superior, 2005.

[3] I. Gómez de Terreros, R. Toro Cebada, J.M. del Río, M. Távora López and M.D. Lanzarote Fernández, "Aplicación de la prueba objetiva tipo test como técnica de autoevaluación continuada y refuerzo pedagógico". II Jornadas Andaluzas de Calidad en la Enseñanza Universitaria. Desarrollo de Planes de Calidad para la Universidad. Materiales para la Calidad, 323-327,2000.

[4] D. Dolz Algaba, I. Peñarrocha Alós and R. Sanchis Llopis, "Experiencias de evaluación automatizada en identificación y ajuste de PID", XXXVII Jornadas de Automática, Madrid, 2016.

[5] J.A. Méndez and E.J. Gonzalez, "Implementing motivational features in reactive blended learning: Application to an introductory control engineering course". IEEE Transactions on Education, 54(4), 619-62, 2011.

[6] S. Uran, D. Hercog and K. Jezernik, "Remote control laboratory with Moodle booking system", 2007 Symposium on Industrial Electronics 2007, 2978-2983, 2007. 